\title{
Assessing the Reliability of Quantitative Fatty Acid Signature Analysis and Compound-Specific Isotope Analysis-Based Mixing Models for Trophic Studies
}

\author{
Igor Prokopkin ${ }^{1}\left(\mathbb{D}\right.$, Olesia Makhutova ${ }^{1,2, * \mathbb{D}}$, Elena Kravchuk ${ }^{1}$, Nadezhda Sushchik ${ }^{1,2}$, Olesia Anishchenko ${ }^{1}$ \\ and Michail Gladyshev ${ }^{1,2}$ (D) \\ 1 Institute of Biophysics, Krasnoyarsk Scientific Center, Siberian Branch, Russian Academy of Sciences, \\ 660036 Krasnoyarsk, Russia; prokop@ibp.ru (I.P.); phytolena@gmail.com (E.K.); labehe@ibp.ru (N.S.); \\ hydrakr@rambler.ru (O.A.); glad@ibp.ru (M.G.) \\ 2 Siberian Federal University, 660041 Krasnoyarsk, Russia \\ * Correspondence: makhutova@ibp.krasn.ru; Tel.: +7-905-973-07-09
}

Citation: Prokopkin, I.; Makhutova, O.; Kravchuk, E.; Sushchik, N.; Anishchenko, O.; Gladyshev, M. Assessing the Reliability of Quantitative Fatty Acid Signature Analysis and Compound-Specific Isotope Analysis-Based Mixing Models for Trophic Studies. Biomolecules 2021, 11, 1590. https:// doi.org/10.3390/biom11111590

Academic Editor: Vladimir N. Uversky

Received: 30 September 2021 Accepted: 25 October 2021 Published: 27 October 2021

Publisher's Note: MDPI stays neutral with regard to jurisdictional claims in published maps and institutional affiliations.

Copyright: (c) 2021 by the authors. Licensee MDPI, Basel, Switzerland. This article is an open access article distributed under the terms and conditions of the Creative Commons Attribution (CC BY) license (https:// creativecommons.org/licenses/by/ $4.0 /)$.

\begin{abstract}
The study of the trophic relationships of aquatic animals requires correct estimates of their diets. We compared the quantitative fatty acid signature analysis (QFASA) and the isotope-mixing model IsoError, based on the compound-specific isotope analysis of fatty acids (CSIA-FA), which are potentially effective models for quantitative diet estimations. In a 21-day experiment, Daphnia was fed a mixture of two food items, Chlorella and Cryptomonas, which were supplied in nearly equal proportions. The percentages and isotope values of the FAs of the algal species and Daphnia were measured. The IsoError based on CSIA-FA gave an estimation of algae consumption using only one FA, 18:3n-3. According to this model, the proportion of consumption of Chlorella decreased while the proportion of consumption of Cryptomonas increased during the experiment. The QFASA model was used for two FA subsets-the extended-dietary subset, which included sixteen FAs, and the dietary one, which included nine FAs. According to both subsets, the portion of consumed Chlorella decreased from Day 5 to 10 and then increased at Day 21. The comparison of the two model approaches showed that the QFASA model is a more reliable method to determine the contribution of different food sources to the diet of zooplankton than the CSIA-based mixing model.
\end{abstract}

Keywords: CSIA-based mixing model; IsoError; QFASA; Daphnia; fatty acids; food

\section{Introduction}

The study of the trophic relationships and the foraging behavior of animals requires correct estimates of their diets. In addition to direct observations of feeding behavior, which are especially problematic for aquatic animals, there are established methods of diet estimation, e.g., visual (microscopic) analysis of stomach contents and feces. However, these approaches have several shortcomings. For instance, the analysis of stomach content may reveal mainly the indigestible parts of prey without showing easily digested food sources [1,2]. Moreover, many ingested types of prey stay viable after gut passage [3-6]. Furthermore, stomach contents and feces represent only recently consumed food sources rather than longer-term diet [2,7]. These limitations of the traditional methods can be overcome using stable isotopes and biochemical molecules, such as fatty acids (FAs), as well as their combination, through compound specific isotope analysis (CSIA), which is used to study assimilated food consumed over a comparatively long time span [7-15].

Stable isotope analysis (SIA) involves the measurement of the isotopic compositions of consumer tissues and probable food sources followed by calculation of consumer diets using isotope mixing models [16]. This method was used to establish the important role of terrestrial food sources in the diet of the freshwater pearl mussel (Margaritifera margaritifera) [17]. Additionally, isotope mixing models have enabled estimation of the total 
contribution of invasive quagga mussel (Dreissena rostriformis bugensis) to the diet of the invasive fish round goby (Neogobius melanostomus) and the native fish ruffe (Gymnocephalus cernuus) [18].

In most studies, where two isotope values, namely, $\delta^{13} \mathrm{C}$ and $\delta^{15} \mathrm{~N}$, are used, the isotope mixing model provides the mathematical solution for only three or fewer food sources [2]. To overcome this limitation, in the last decade, special Bayesian-based approaches have been developed for cases with many $(>3)$ food sources [19]. This type of approach revealed changes in the diet, which included four food sources, of the freshwater shrimp Paratya australiensis inhabiting ecosystems differing in the availabilities of autochthonous and allochthonous organic matter [20]. The Bayesian models use probability distributions of the compounds (isotopes) to estimate the contributions of multiple food sources to the diets of consumers. However, the accuracy of the outcomes of these models is limited by the number of compounds used; an increase in the number of compounds used appears to be the only way to achieve reasonably accurate estimates of the contributions of multiple food sources [21].

An increase in the number of food compounds, up to 40 , may be achieved by using FAs instead of stable isotopes [2,7,13]. For instance, quantitative fatty acid signature analysis (QFASA) was successfully used to study the diets of different seal species [7], spectacled and Steller's eider [9], Atlantic salmon [11], New Zealand sea lions [22], polar bears [23], flatfish [24], and steelhead trout [25]. A modification of the isotope mixing model, MixSIR, referred to as the FASTAR model, has been developed, which calculates the contribution of food sources to predator diets based on their FA composition [2]. Recently, a new generation of the Bayesian mixing model, MixSIAR, which employs a set of parameterizations that unify the MixSIR error structure, has been used with FA data to quantify the dietary components of spectacled and Steller's eider, Atlantic salmon, tufted puffin, harp and harbour seals [13], and various fish species and aquatic invertebrates [26].

The FA biomarker-based approach was shown to provide better results to infer consumer diets than did the common two-tracer SIA approach [2]. However, there were no attempts made to compare the FA-based mixing models with a combination of the FA and SIA methods, namely CSIA, for the evaluation of the diets of aquatic consumers. Therefore, the aim of our study was to compare the application of QFASA with CSIA-based mixing models for inferring the diet of Daphnia in a controlled feeding experiment.

\section{Materials and Methods}

\subsection{Cultivation of Organisms}

The methods of cultivation are described in a study by Gladyshev et al. [27]. Briefly, a stock culture of Daphnia galeata Sars (collection of the Institute of Biophysics SB RAS, Krasnoyarsk, Russia), was maintained at $20-26^{\circ} \mathrm{C}$ and fed Chlorella vulgaris Beijer (collection of the Institute of Biophysics SB RAS, Krasnoyarsk, Russia). For certain conditions of the experiment, D. galeata was fed both C. vulgaris and Cryptomonas sp. (collection of the I.D. Papanin Institute for Biology of Inland Waters RAS, Borok, Russia). Batch cultures of C. vulgaris and Cryptomonas sp. were grown at $18-22{ }^{\circ} \mathrm{C}$ and an illumination of 6000 lux (16:8 h light:dark cycle).

\subsection{Preparation of Food}

As in our previous work [27], algae from the batch cultures were concentrated by centrifugation and separated from the medium. The feeding mixture was prepared from the concentrated algae by dilution to obtain a concentration $\sim 1 \mathrm{mg} \mathrm{L}^{-1}$ of organic carbon $[10,27]$.

\subsection{Experiments}

The experiment was conducted under dim light (16:8 h light:dark cycle) at $20^{\circ} \mathrm{C}$. Six 1-L jars placed into a 'plankton wheel' (diameter, $38 \mathrm{~cm}, 0.2 \mathrm{rpm}$ ) [28] were used. In each jar, $418 \pm 3$ individuals of Daphnia of various ages and sizes were placed to simulate a 
natural population. The average biomass in each jar was $33.0 \pm 1.6 \mathrm{mg}$ of wet mass. Each day, $50 \%$ of the medium in each jar was replaced by a new portion of the algal feeding suspension to obtain a final concentration in the jars of $\sim 1 \mathrm{mg} \mathrm{L}^{-1}$ of organic carbon.

Three runs of the experiment were performed. The first two runs lasted 10 days, while the third, Run III, lasted 21 days. In each run, in 2 jars the food was Chlorella, in 2 jars the food was Cryptomonas, and in 2 jars the food was a mixture of Chlorella and Cryptomonas, approximately 1:1 by organic carbon. The Daphnia fed Chlorella, Cryptomonas, and the mixture of these, were designated as Daphnia (Chl), Daphnia (Cry), and Daphnia (Mix), respectively.

Samples of algae for conducting the FA and CSIA analyses were taken from the batch cultures that were used for the preparation of food. Although the batch cultures were kept under the same stable conditions throughout the experiment and, therefore, were assumed to have similar FA and isotope compositions, samples (replicates) were collected from the batch cultures at different time points throughout the experiment, i.e., three samples were taken at Days 1, 4, and 7 of each run (Figure 1). In addition, two further samples were taken from the mixture at Day 15 in Run III (Figure 1). Thus, in total, 9 replicates were performed for each mono-species algae and 11 replicates for their mixture (Figure 1).

\section{Number of samples for each item}
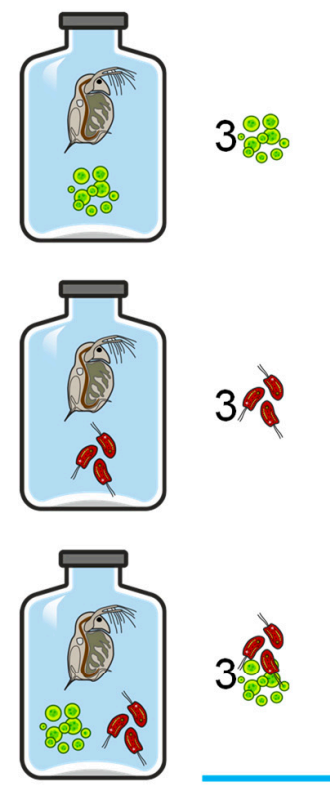
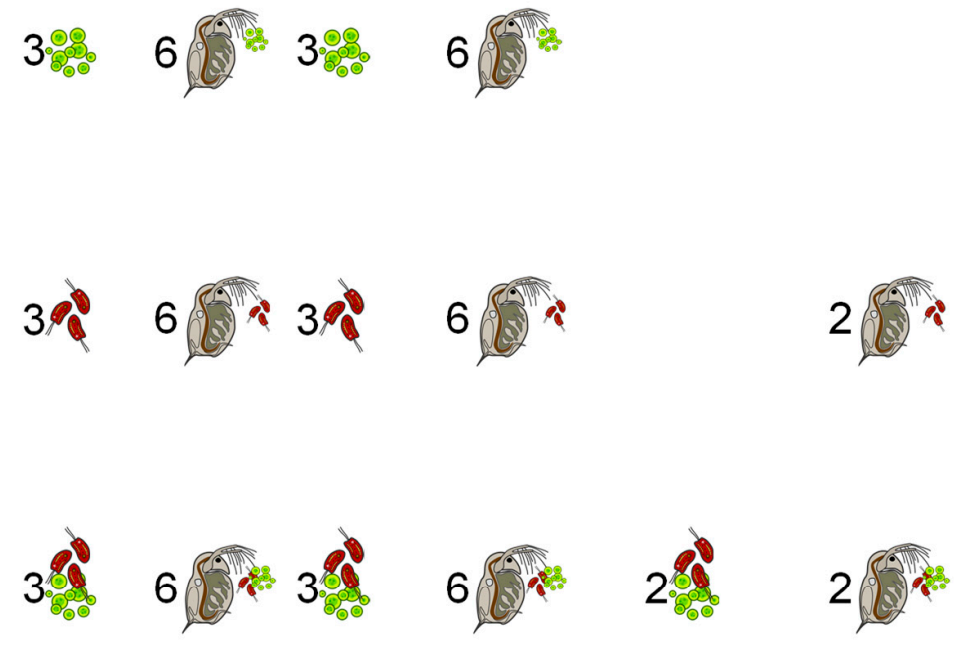

21

\section{Total number} of samples
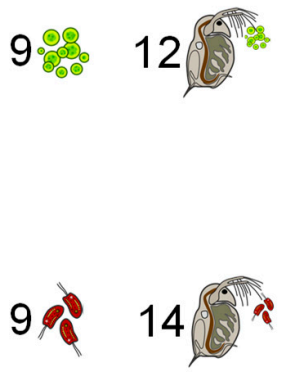

11 思

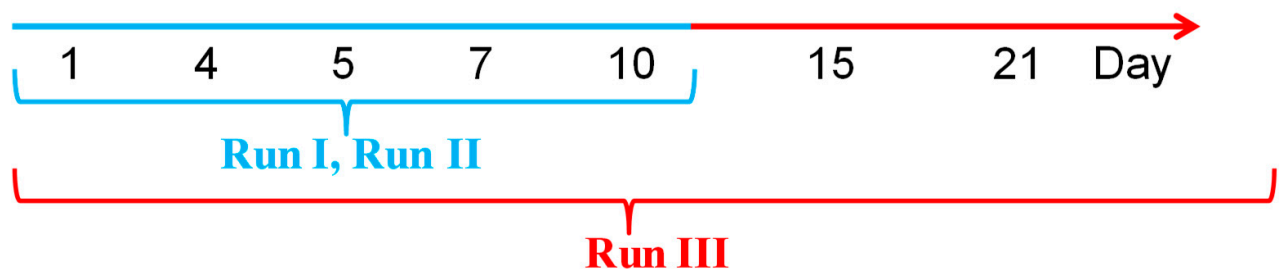

Figure 1. The experimental design with the number of samples taken for fatty acid and compound specific isotope analyses during the experiment.

Samples of Daphnia for FA analysis and CSIA were taken from each 1-L 'plankton wheel' jar at Days 5 and 10 of each run (Figure 1). Additionally, two samples of Daphnia (Cry) and Daphnia (Mix) were taken at Day 21 in Run III (Figure 1). In total, 12 samples of Daphnia (Chl), 14 samples of Daphnia (Cry), and 14 samples of Daphnia (Mix) were taken (Figure 1). In addition, two samples from the stock culture of Daphnia were taken, designated below as Daphnia (0). 


\subsection{Fatty Acid Sampling and Analyses}

The sampling of the algae cultures included their collection and conservation in chloroform:methanol $(2: 1, \mathrm{v}: \mathrm{v})$, while the sampling of Daphnia included gutting, concentration, and conservation. The methods have been described in detail in our previous work [27].

The fatty acid analysis included homogenization of samples, lipid extraction, and fatty acid methylation. The methods have been described in detail elsewhere [29]. The description of the gas chromatograph and chromatographic and mass-spectrometric conditions can be found in studies by Gladyshev et al. [27,30].

\subsection{Compound Specific Isotope Analyses}

The analyses of compound specific isotopes were conducted using a Trace GC Ultra (Thermo Electron, Waltham, MA, USA) gas chromatograph coupled with a Delta V Plus isotope ratio mass spectrometer (Thermo Fisher Scientific Corporation, Waltham, MA, USA) via a type-III combustion interface. The method of CSIA-FA has been described in detail in studies by Gladyshev et al. [27,31].

\subsection{Isotope Mixing Models}

These models are based on the following system of equations:

$$
\begin{gathered}
\sum_{i=1}^{n} f_{i}=1, \\
\delta_{\text {mix }, j}=\sum_{i=1}^{n} f_{i} \cdot\left(\delta_{i, j}+\gamma_{i}\right), j=1 \ldots m,
\end{gathered}
$$

where $n$ is the number of food sources, $m$ is the number of isotopes, $f_{i}$ is the proportional contribution of the $i$-th food source to diet of the consumer, $\gamma_{i}$ is the isotope fractionation of the $i$-th food source, $\delta_{m i x, j}$ is the $j$-th isotopic signature of the consumer, $\delta_{i, j}$ is the $j$-th isotopic signature of the $i$-th food source.

Equation (1) implies that there are no other food sources except the sources considered in it. Equation (2) shows the mass-balance composition for isotopic signatures of the consumer. For simplicity, $f_{i}$ is a constant for all $m$ isotopes. Fractionation $\gamma_{i}$ is also assumed to be constant for all $m$ isotopes [19].

When the number of food sources is less than or equal to the number of isotopes plus 1, the system of Equations (1) and (2) is solved with unique values of the proportional contributions of food sources to the diet of the consumer [32]. These contributions of food sources to the diet are quantified using different algebraic or geometrical methods $[16,33]$.

In other cases, when the number of food sources exceeds the number of isotopes plus 1 , the system of Equations (1) and (2) has no unique solution. There are several different approaches for estimating contributions of food sources to the diet in such situations. For example, the number of food sources can be reduced by combining them in groups containing the closest values of isotopic signatures or with some logical or biological connection or meaning [34]. Another approach is to use the mixing models with a Bayesian statistical framework, which enables estimation of the probability distributions of food sources in the diet of predators $[19,35]$.

Most commonly, the isotopic compositions of the bodies or tissues of a consumer and food sources are used for model estimation of diet [16]. However, a simple two-source mixing model can also be applied for CSIA-FA to estimate the contributions of different food sources to the diet of laboratory-cultured Daphnia [10].

\subsection{FA Selection for Isotope Mixing Modeling}

Only FAs common both to food sources and to the consumer can be used for the isotope mixing model based on CSIA-FA. Furthermore, these fatty acids must be essential FAs, i.e., the consumer cannot synthesize them de novo. In our experiment, only three FAs met the above requirements: $16: 3 n-3,18: 2 n-6$, and 18:3n-3. 


\subsection{Isotope Mixing Model Routine}

The first step in the model calculation was the correction of isotope values [36] (Table 2.1) of the food (algae) by adding fractionation coefficients to the measured average $\delta^{13} \mathrm{C}$ values of each FA. The fractionation coefficient for each individual FA $i$ and for each individual diet $j, \Delta \delta^{13} C A_{i j}$, was calculated as the difference between the $\delta^{13} \mathrm{C}$ value of FA in Daphnia $\left(\delta^{13} \mathrm{CFA}_{D i j}\right)$ and in its $\operatorname{diet}\left(\delta^{13} \mathrm{CFA}_{i j}\right)[10]$ :

$$
\Delta \delta^{13} \mathrm{CFA}_{i j}=\delta^{13} \mathrm{CFA}_{D i j}-\delta^{13} \mathrm{CFA}_{i j}
$$

The second step was to calculate proportional contributions of the food sources to the diet of Daphnia using the mixing model IsoError by Phillips and Gregg [37]. The version for single isotope and two food sources was executed using Microsoft Excel (https: / /www.epa. gov / eco-research/stable-isotope-mixing-models-estimating-source-proportions, accessed on 17 April 2021).

\subsection{Quantitative Fatty Acid Signature Analysis (QFASA)}

QFASA is a statistical model that quantitatively estimates the predator diets using the FA composition of the predator and its food sources. The model takes a weighted mixture of the FA levels (\% of total FAs) of the food sources and determines the mixture that most closely resembles the consumer FA composition [7]. The weighting coefficients that best explain the fatty acid composition of the predator correspond to the estimated proportion of the food sources in the predator diet.

Vector $\hat{y}$ (the theoretical proportions of $\hat{y}_{j}$ of each $j$-th fatty acid of the predator) is related to vector $\hat{x}_{k}$, consisting of the elements $\hat{x}_{k j}$ (the mean proportion of the $j$-th fatty acid of the $k$-th food source), via the following equation:

$$
\hat{y}=\sum_{k} p_{k} \cdot \hat{x}_{k}
$$

where $p_{k}$ is the estimated proportion of the $k$-th food source in the predator diet.

The estimation task is to choose the $p_{k}$ values such that the model estimation $\hat{y}$ is as close as possible to the real measured profile $y$ [7]. For this purpose, the Kulback-Liebler $(K L)$ distance for comparing $\hat{y}$ and $y$ is used:

$$
K L=\sum_{j}\left(y_{j}-\hat{y}_{j}\right) \cdot \log \left(\frac{y_{j}}{\hat{y}_{j}}\right)
$$

The result of modelling is the set of $p_{k}$ that gives the smallest $K L$ distance. This set is considered as the estimated diet of the predator.

\subsection{Calculation of Calibration Coefficients for the QFASA Model}

Following Iverson et al. [7], calibration coefficients, CC, are introduced to the model calculations to take into account consumer metabolism. These coefficients are determined for each common FA, and their values are obtained as the ratio of the amounts (levels) of the FAs in the consumers and in their food [11]:

$$
C C=F A \text { level in consumer } / F A \text { level in food }
$$

In our experiment, two food items were used: Chlorella and Cryptomonas. Thus, two sets of CCs were calculated.

\subsection{Selection of FA Subsets for the QFASA Model}

A further concept, which is used in the QFASA model to increase the accuracy of calculation of diets, involves consideration of the fact that there are two groups of FAs: (1) "extended-dietary" FAs, i.e., the FAs synthesized by the consumer and obtained by 
consumption of food; (2) FAs of dietary origin [7]. Each FA selected for the model must be present at a level of $>0.1 \%$ in at least one food item or in the consumer [11]. Based on the above conditions, in our experiment, two subsets of FAs were selected for the QFASA model calculations. The first subset included the "extended-dietary" FAs: 12:0, 14:0, 16:0, 16:1n-9, 16:1n-7, 16:2n-6, 16:2n-4, 16:3n-3, 16:4n-3, 18:0, 18:1n-9, 18:2n-6, 18:3n-3, 18:4n-3, $18: 5 n-3,20: 5 n-3$. The second subset included the dietary FAs: $16: 2 n-6,16: 2 n-4,16: 3 n-3$, $16: 4 n-3,18: 2 n-6,18: 3 n-3,18: 4 n-3,18: 5 n-3,20: 5 n-3$.

\subsection{The QFASA Model Routine}

Four calculation scenarios were used: (1) Chlorella CC $\times 2$ FA subsets; (2) Cryptomonas $C C \times 2$ FA subsets. The model computations were performed in R 3.3 .3 [38] (R Core Team, 2016), RStudio 1.0.136 [39] (RStudio Team, 2016), using the R package QFASA [7].

\subsection{Statistical Analyses}

Standard deviations (SD), standard errors (SE), Student's $t$-test, and one-way ANOVA with Tukey HSD post hoc tests were calculated using STATISTICA software, version 9.0 (StatSoft, Inc., Tulsa, OK, USA).

\section{Results}

Across all samples, 43 FAs were identified. Quantitatively and qualitatively prominent FAs of the algae are shown in Figure 2. The percentages of all fatty acids in the biomass of each alga and their mixture were normally distributed. Chlorella and Cryptomonas had FA compositions typical for green and cryptophyte algae, respectively. Specifically, Chlorella had high levels of 16:2n-6, 16:3n-3, 18:2n-6, and 18:3n-3, while Cryptomonas had high levels of 18:4n-3, 20:5n-3, 22:5n-6, and 22:6n-3 (Figure 2). In the mixture, these FAs had intermediate levels (Figure 2$)$, i.e., the mixture that was equalized by organic carbon $(\sim 1: 1)$ appeared to be equalized also by the typical fatty acid composition ( 1:1, Figure 2$)$.

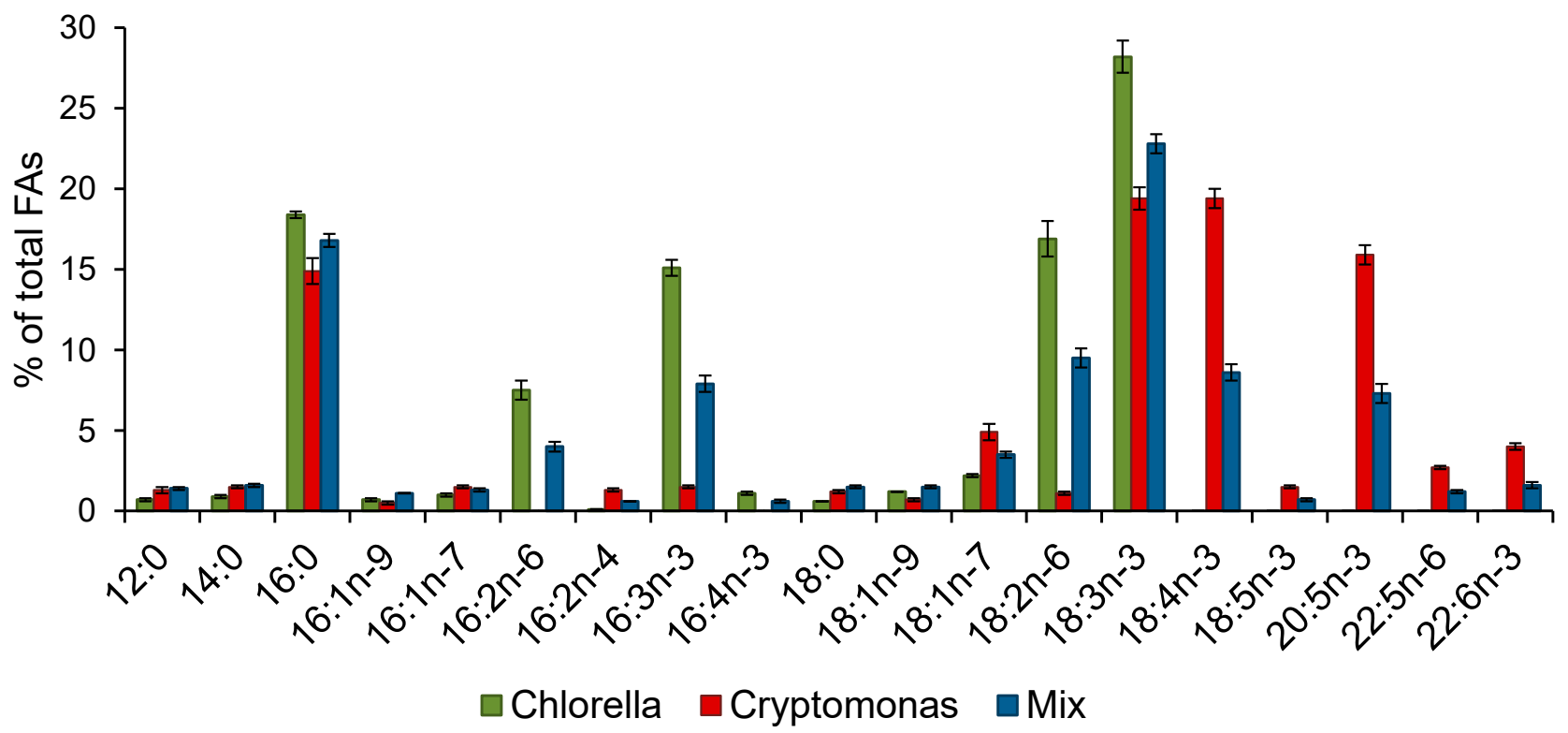

Figure 2. Mean values ( \pm standard errors $(\mathrm{SE})$ ) of percentages of quantitatively prominent fatty acids (FAs) (\% of total FAs) in biomass of Chlorella vulgaris (numbers of samples, $n=9)$, Cryptomonas sp. $(n=9)$ and their mixture $(n=11)$.

Quantitatively and qualitatively prominent FAs of Daphnia are given in Figure 3. Average percentages of 12:0, 14:0, 16:0, 16:1n-7, 18:0, and 18:1n-7 tended to decrease in all three treatments, Daphnia (Chl), Daphnia (Cry), and Daphnia (Mix), from Day 5 to 10 and to 21 (Figure 3b-d). By contrast, percentages of 18:3n-3 tended to increase during the course of the experiment in all treatments but the increase was only statistically significant in Daphnia 
(Chl) $(p<0.05)$ (Figure 3a). Percentages of 16:2n-6 and 16:3n-3 increased significantly at Day 10 in Daphnia $(\mathrm{Chl})(p<0.05)$ (Figure 3a). Stearidonic acid $(18: 4 n-3)$ was not detected in Chlorella and Daphnia (Chl) but was abundant in Cryptomonas and increased significantly in Daphnia (Cry) and Daphnia (Mix) from Day 5 to $10(p<0.05)$ (Figure 3b). Similarly, 20:5n-3 was not detected in Chlorella and was present at a comparatively low level in Daphnia (Chl) but was abundant in Cryptomonas and increased significantly in Daphnia (Cry) and Daphnia (Mix) from Day 5 to $10(p<0.05)$ (Figure 3b). Percentages of 16:4n-3 increased significantly at Day 21 in Daphnia (Cry) $(p<0.05)$ (Figure 3d). The other FAs had no clear patterns of variations (Figure 3). The total FA content (mg/g, wet weight) in Daphnia was $6.9 \pm 1.0$ at the beginning of the experiments; in Daphnia (Chl)—8.1 \pm 0.5 at Day 5 and $10.2 \pm 0.7$ at Day 10; in Daphnia (Cry) -9.8 \pm 0.7 at Day 5, $10.6 \pm 1.1$ at Day 10, and $14.6 \pm 1.5$ at Day 21; in Daphnia (Mix) - 8.1 \pm 0.6 at Day 5, $9.8 \pm 0.6$ at Day 10, and $13.9 \pm 0.4$ at Day 21. Thus, the total FA content did not decrease in any treatment during the experiment, which implies that the Daphnia was not carbon-limited.

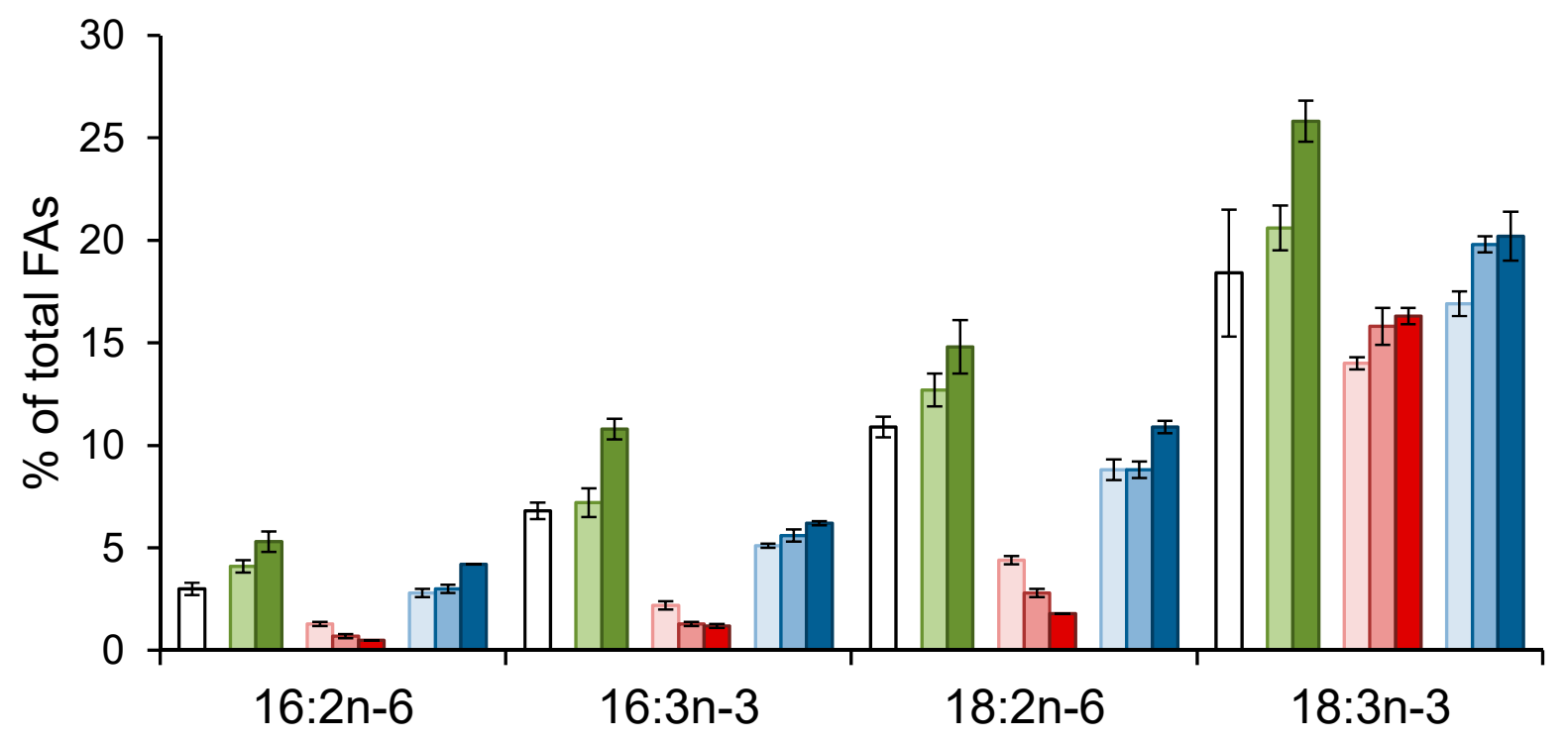

(a)

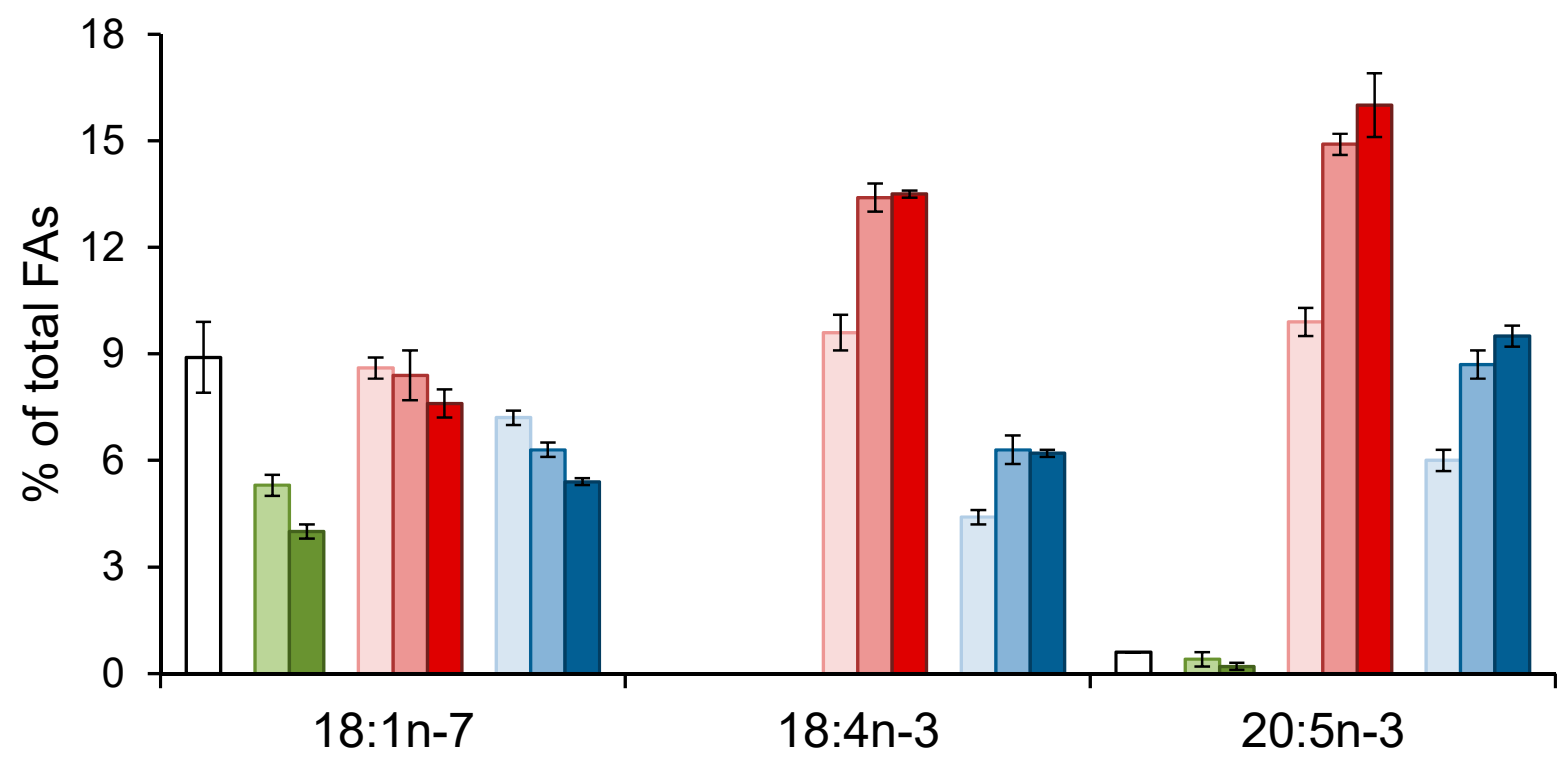

(b)

Figure 3. Cont. 


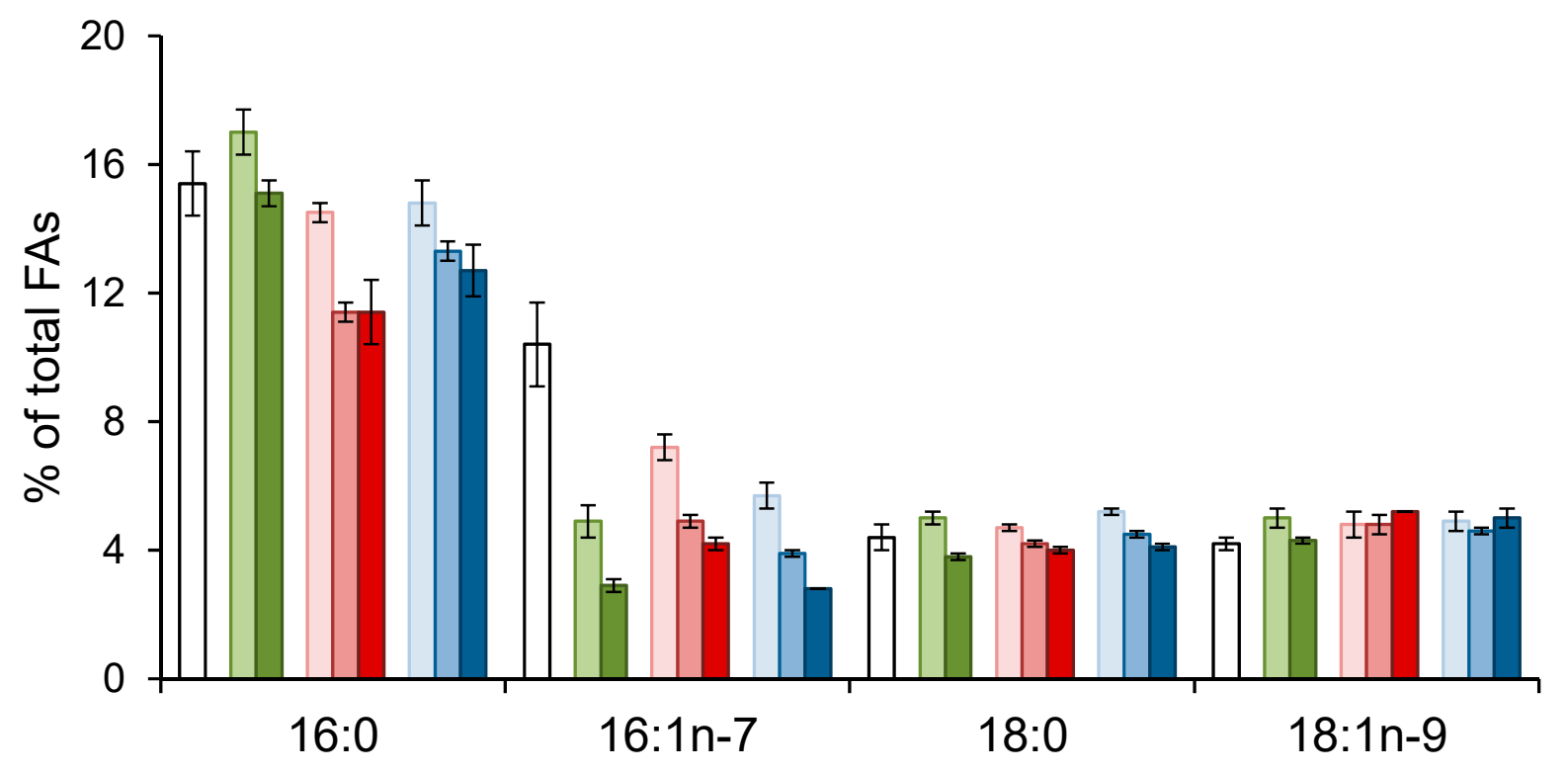

(c)

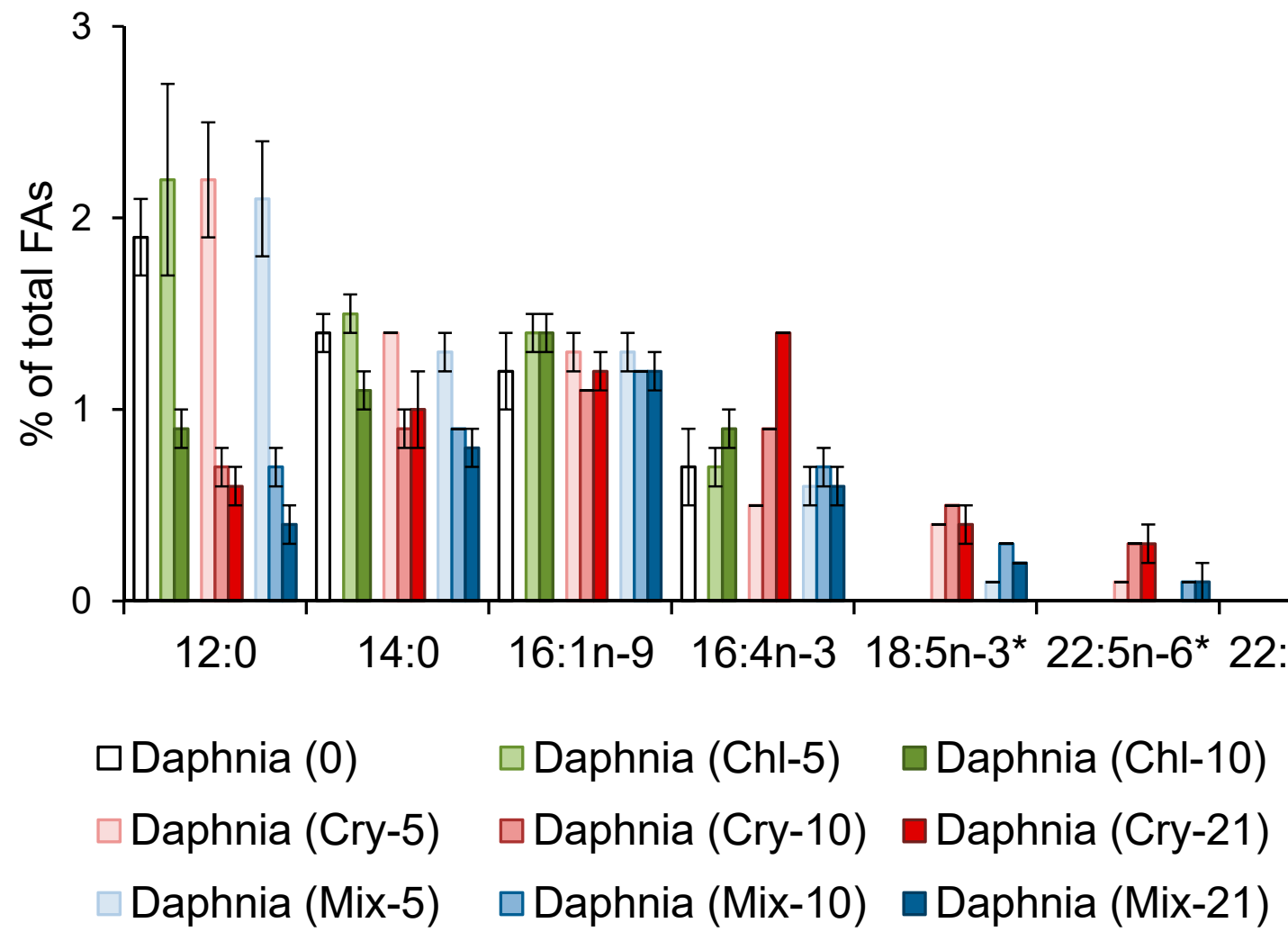

(d)

Figure 3. Mean values (\% of the total FAs \pm SE) of FAs in Daphnia fed Chlorella (Chl), Cryptomonas (Cry), and their mixture (Mix) at Days 5, 10, and 21 of the experiment, and in the stock culture (0). (a) FAs that were higher in Chlorella; (b) FAs that were higher in Cryptomonas; (c) dominant saturated and monounsaturated FAs; (d) minor FAs. Non-normally distributed variables are marked with *.

Values of the isotopes of all FAs in Daphnia were normally distributed. Statistically significant differences (fractionation) of the isotope values of many FAs were characteristic of Daphnia (Chl) (Figure 4a), Daphnia (Cry) (Figure 4b), and Daphnia (Mix) (Figure 4c). 


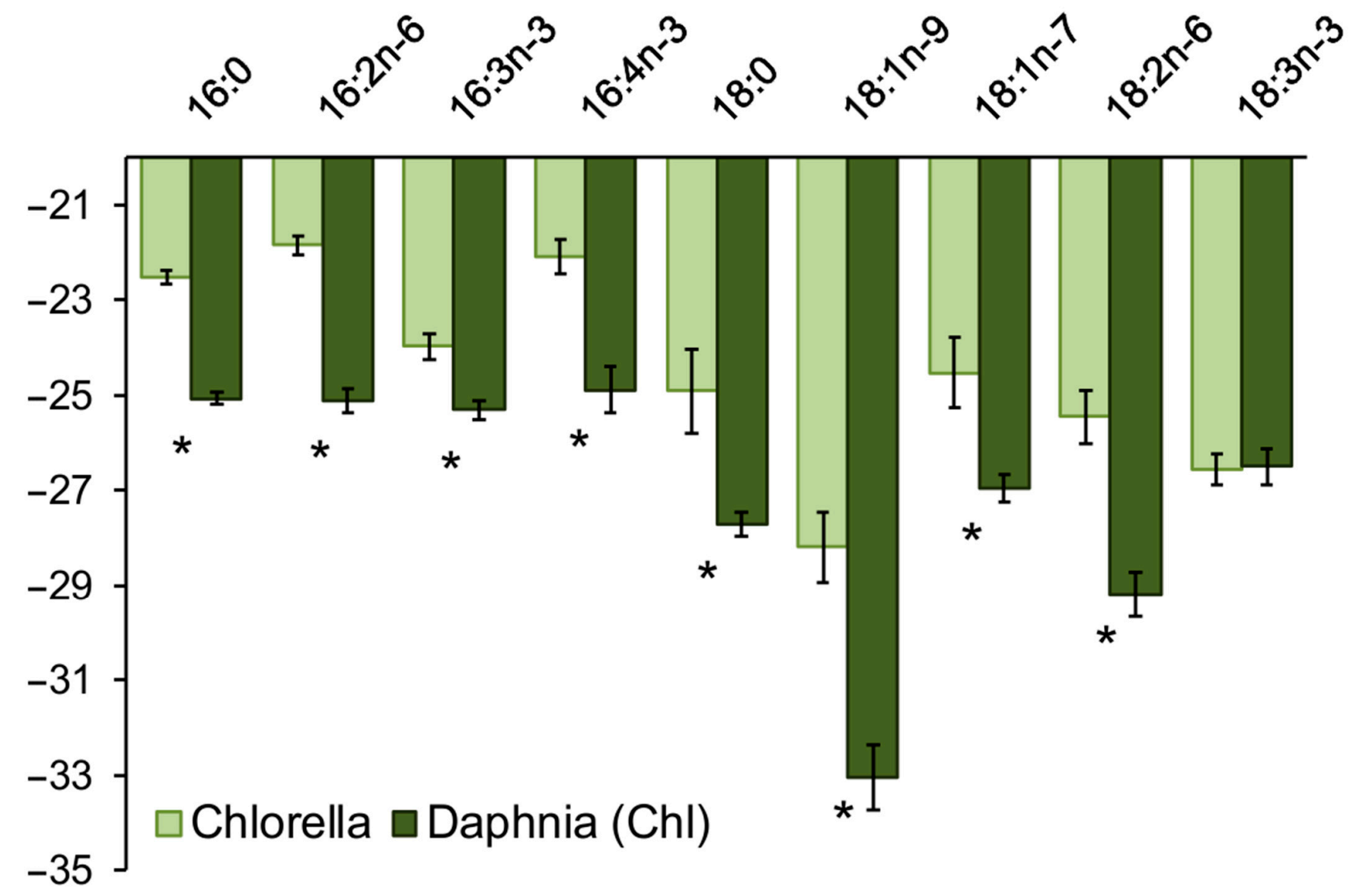

(a)

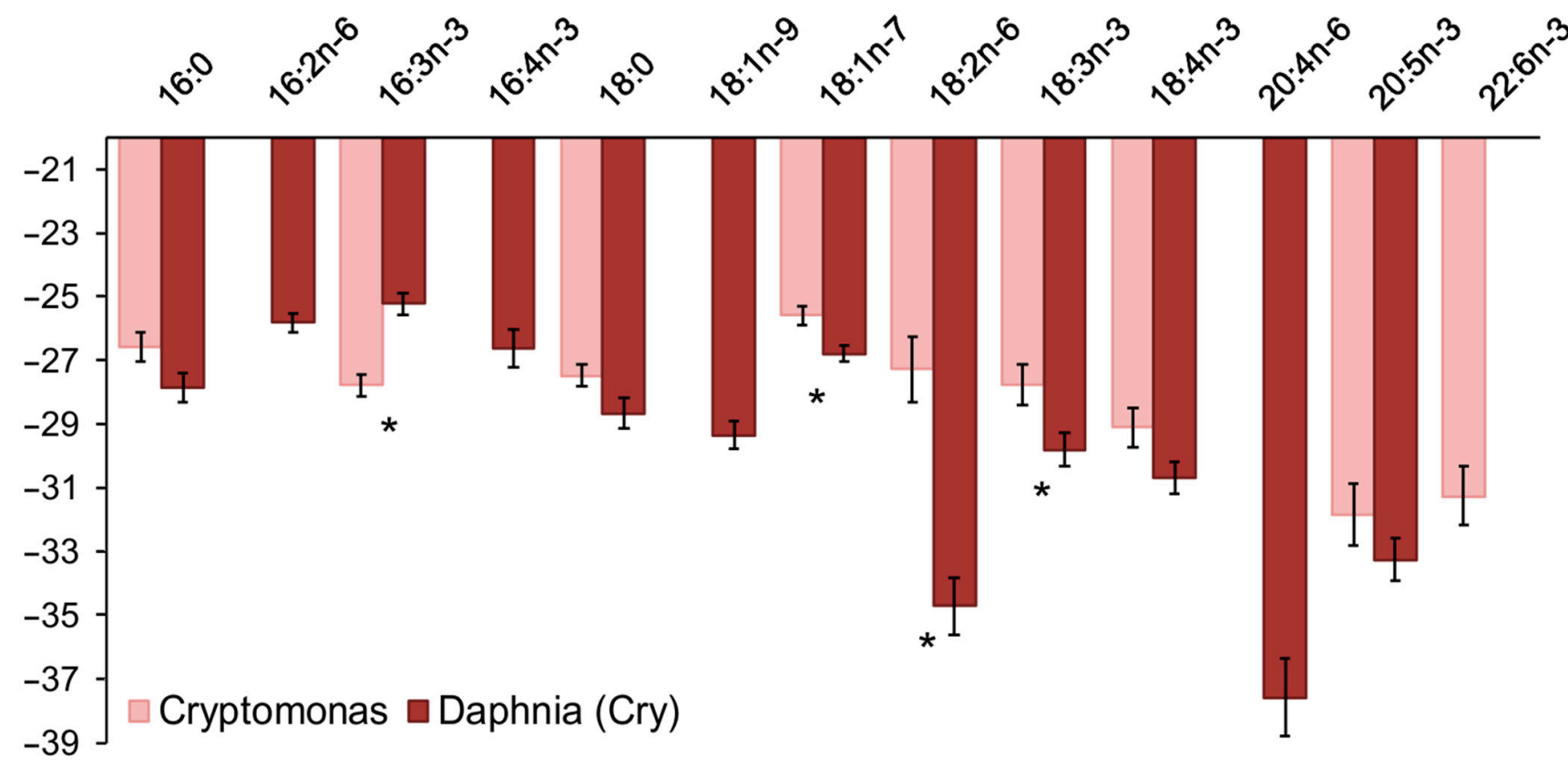

(b)

Figure 4. Cont. 


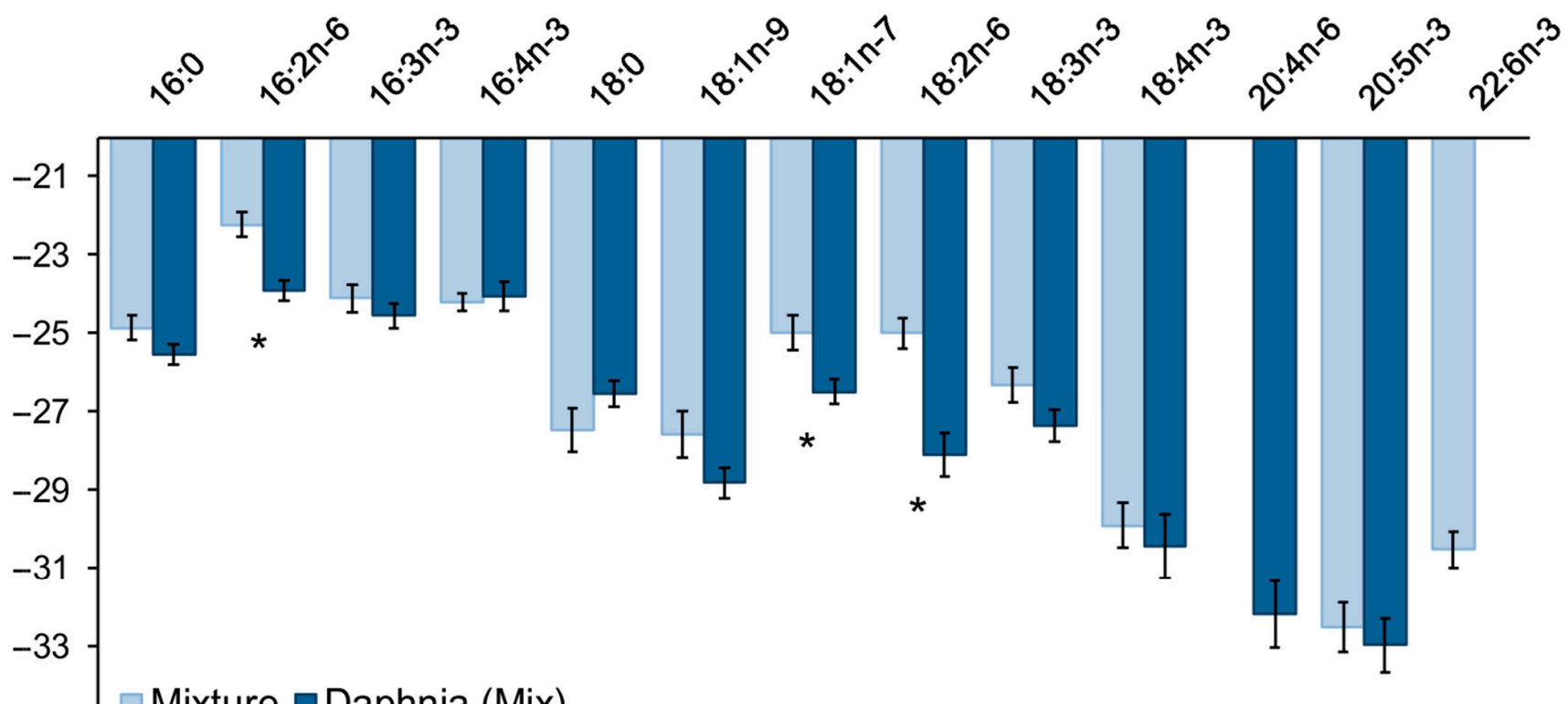

(c)

Figure 4. Average values of stable isotope values of FAs ( \pm SE) in algae and in Daphnia galeata, fed (a) Chlorella vulgaris; (b) Cryptomonas sp.; (c) the mixture of algae. Significant differences according to $t$-test $(p<0.05)$ between algae and Daphnia are marked with *.

Fractionation coefficients (Equation (3)) for the three FAs selected for the isotope mixing modelling are given in Table 1.

Table 1. Fractionation coefficients $\Delta \delta^{13} \mathrm{CFA}$ (\%) for the common essential dietary FAs selected for the isotope mixing model.

\begin{tabular}{|c|c|c|}
\hline \multirow[t]{2}{*}{ FA } & \multicolumn{2}{|c|}{$\Delta \delta^{13} \mathrm{CFA}$} \\
\hline & Chlorella & Cryptomonas \\
\hline $16: 3 n-3$ & -1.34 & 2.55 \\
\hline $18: 2 n-6$ & -3.73 & -7.44 \\
\hline $18: 3 n-3$ & 0.06 & -2.03 \\
\hline
\end{tabular}

The stable isotope ratios of 16:3n-3 and 18:3n-3 gradually decreased during the experiment (Table 2). The stable isotope ratios of 18:3n-3 at Days 10 and 21 in Run III were depleted compared to Run I and Run II (Table 2).

Table 2. Stable isotope composition of FAs selected for isotope mixing modelling in Daphnia galeata fed the mixture of algae: average values $(\mathrm{M}, \%) \pm$ standard deviation (SD).

\begin{tabular}{cccc}
\hline & $\mathbf{1 6 : 3 n - 3}$ & $\mathbf{1 8 : 2 n - 6}$ & $\mathbf{1 8 : 3 n - 3}$ \\
\hline Day 5 & & & -27.57 \\
Run 1 & -24.55 & -30.37 & -29.00 \\
Run 1 & -24.88 & -31.73 & -26.16 \\
Run 2 & -24.16 & -28.76 & -27.47 \\
Run 2 & -24.25 & -28.83 & -25.19 \\
Run 3 & -23.17 & -25.07 & -27.56 \\
Run 3 & -23.2 & -26.26 & $-27.16 \pm 1.32$ \\
M \pm SD & $-24.04 \pm 0.71$ & $-28.50 \pm 2.48$ & \\
\hline
\end{tabular}


Table 2. Cont.

\begin{tabular}{cccc}
\hline & $\mathbf{1 6 : 3 n - 3}$ & $\mathbf{1 8 : 2 n - 6}$ & $\mathbf{1 8 : 3 n - 3}$ \\
\hline Day 10 & & & -27.84 \\
Run 1 & -23.25 & -29.78 & -26.94 \\
Run 1 & -25.87 & -27.88 & -26.31 \\
Run 2 & -24.63 & -27.51 & -25.50 \\
Run 2 & -24.90 & -26.48 & -29.14 \\
Run 3 & -25.14 & -27.00 & -29.55 \\
Run 3 & -26.64 & -27.55 & $-27.55 \pm 1.60$ \\
M SD & $-25.07 \pm 1.15$ & $-27.70 \pm 1.13$ & -29.55 \\
Day 21 & & & -28.11 \\
Run 3 & -25.22 & -29.31 & $-28.83 \pm 1.02$ \\
Run 3 & -26.79 & -27.79 & \\
M SD & $-26.00 \pm 1.11$ & $-28.55 \pm 1.08$ & \\
\hline
\end{tabular}

Input data for the IsoError mixing model, including corrected isotope values of algae and isotope values of Daphnia, are provided in Table 3.

Table 3. Input data for IsoError mixing model: corrected average isotope values $\delta^{13}$ Ccor (\%o, \pm SD) for algae and isotope values $\delta^{13} \mathrm{C}$ for Daphnia.

\begin{tabular}{cccccc}
\hline FA & \multicolumn{2}{c}{$\boldsymbol{\delta}^{\mathbf{1 3}}$ Ccor } & & \multicolumn{2}{c}{$\boldsymbol{\delta}^{\mathbf{1 3}} \mathbf{C}$} \\
& Chlorella & Cryptomonas & Day 5 & Day 10 & Day 21 \\
\hline $16: 3 n-3$ & $-25.31 \pm 0.81$ & $-25.23 \pm 1.03$ & $-24.04 \pm 0.71$ & $-25.07 \pm 1.15$ & $-26.00 \pm 1.11$ \\
$18: 2 \mathrm{n}-6$ & $-29.19 \pm 1.66$ & $-34.72 \pm 3.10$ & $-28.50 \pm 2.48$ & $-27.70 \pm 1.13$ & $-28.55 \pm 1.08$ \\
$18: 3 \mathrm{n}-3$ & $-26.50 \pm 0.99$ & $-29.80 \pm 1.87$ & $-27.16 \pm 1.32$ & $-27.55 \pm 1.60$ & $-28.83 \pm 1.02$ \\
\hline
\end{tabular}

Results of the calculations of the proportions of the two algae consumed by Daphnia fed the 1:1 mixture are given in Table 4. Interpretable results were obtained only using 18:3n-3, while results based on 16:3n-3 and 18:2n-6 were non-interpretable (Table 4). According to the calculations, the proportion of consumption of Chlorella decreased, while the proportion of consumption of Cryptomonas increased from Day 5 to 21 of the experiment (Table 4).

Table 4. Results of calculation by IsoError mixing model using isotope values of three common essential dietary FAs: average proportions of consumption of two algae species ( $\pm \mathrm{SE}, \%)$ by Daphnia at Days 5, 10, and 21 of the experiment.

\begin{tabular}{ccccc}
\hline FA & Alga & \multicolumn{3}{c}{ Source Proportion } \\
& & Day 5 & Day 10 & Day 21 \\
\hline \multirow{2}{*}{ 16:3n-3 } & Chlorella & $-1491.1 \pm 8523.1$ & $-196.0 \pm 1553.4$ & $970.1 \pm 5080.5$ \\
& Cryptomonas & $1591.1 \pm 8523.1$ & $296.0 \pm 1553.4$ & $-870.1 \pm 5080.5$ \\
\multirow{2}{*}{$18: 2 \mathrm{n}-6$} & Chlorella & $112.5 \pm 21.7$ & $127.0 \pm 16.0$ & $111.6 \pm 17.9$ \\
& Cryptomonas & $-12.5 \pm 21.7$ & $-27.0 \pm 16.0$ & $-11.6 \pm 17.9$ \\
18:3n-3 & Chlorella & $80.1 \pm 18.6$ & $68.3 \pm 21.7$ & $29.4 \pm 25.8$ \\
& Cryptomonas & $19.9 \pm 18.6$ & $31.7 \pm 21.7$ & $70.6 \pm 25.8$ \\
\hline
\end{tabular}

Calibration coefficients (CC) calculated for the QFASA model are given in Table 5.

The QFASA model calculations for the subset of extended-dietary FAs resulted in the proportion of Chlorella in the diet of between $42.63 \%$, when CC based on Cryptomonas were used, and $70.28 \%$, when CC based on Chlorella were used (Table 6). 
Table 5. Calibration coefficients (CC) for the QFASA model for Chlorella (Chl) and Cryptomonas (Cry) calculated from data presented in Figures 2 and 3 (see Methods for details).

\begin{tabular}{ccc}
\hline FA & CC (Chl) & CC (Cry) \\
\hline $12: 0$ & 1.26 & 0.46 \\
$14: 0$ & 1.24 & 0.66 \\
$16: 0$ & 0.82 & 0.77 \\
$16: 1 n-9$ & 1.99 & 2.57 \\
$16: 1 n-7$ & 2.77 & 2.80 \\
$16: 2 n-6$ & 0.70 & \\
$16: 2 n-4$ & 0.81 & 0.14 \\
$16: 3 n-3$ & 0.72 & 0.76 \\
$16: 4 n-3$ & 0.79 & 35.33 \\
$18: 0$ & 6.11 & 3.32 \\
$18: 1 n-9$ & 3.55 & 7.82 \\
$18: 1 n-7$ & 1.84 & 1.56 \\
$18: 2 n-6$ & 0.88 & 1.66 \\
$18: 3 n-3$ & 0.91 & 0.84 \\
$18: 4 n-3$ & & 0.70 \\
$18: 5 n-3$ & & 0.27 \\
$20: 5 n-3$ & & 1.01 \\
$22: 5 n-6$ & & 0.11 \\
$22: 6 n-3$ & & 0.08 \\
\hline
\end{tabular}

Table 6. Estimation ( $\mathrm{M} \pm \mathrm{SD}, \%$ ) of the diet of Daphnia galeata by the QFASA model using extendeddietary subset of FAs (12:0, 14:0, 16:0, 16:1n-9, 16:1n-7, 16:2n-6,16:2n-4, 16:3n-3, 16:4n-3, 18:0, 18:1n-9, 18:2n-6, 18:3n-3, 18:4n-3, 18:5n-3, 20:5n-3). CC-calibration coefficients for Chlorella (Chl) and Cryptomonas (Cry).

\begin{tabular}{ccccc}
\hline \multirow{2}{*}{ Days } & \multicolumn{2}{c}{ CC (Chl) } & \multicolumn{2}{c}{ CC (Cry) } \\
& Chlorella & Cryptomonas & Chlorella & Cryptomonas \\
\hline 5 & $70.28 \pm 2.80$ & $29.72 \pm 2.80$ & $54.25 \pm 4.32$ & $45.75 \pm 4.32$ \\
10 & $60.99 \pm 3.42$ & $39.01 \pm 3.42$ & $42.63 \pm 3.88$ & $57.37 \pm 3.88$ \\
21 & $65.21 \pm 0.14$ & $34.79 \pm 0.14$ & $48.02 \pm 0.43$ & $51.98 \pm 0.43$ \\
\hline
\end{tabular}

The model calculations for the subset of dietary FAs gave the proportion of Chlorella in the diet of between $43.43 \%$, when CC based on Cryptomonas were used, and $70.95 \%$, when CC based on Chlorella were used (Table 7). In all variants of calculations, the portion of consumed Chlorella decreased from Day 5 to 10 and then increased at Day 21 (Tables 6 and 7).

Table 7. Estimation ( $\mathrm{M} \pm \mathrm{SD}, \%$ ) of the diet of Daphnia galeata by the QFASA model using dietary subset of FAs (16:2n-6, 16:2n-4, 16:3n-3, 16:4n-3, 18:2n-6, 18:3n-3, 18:4n-3, 18:5n-3, 20:5n-3).

\begin{tabular}{ccccc}
\hline \multirow{2}{*}{ Days } & \multicolumn{2}{c}{ CC (Chl) } & \multicolumn{2}{c}{ CC (Cry) } \\
& Chlorella & Cryptomonas & Chlorella & Cryptomonas \\
\hline 5 & $70.95 \pm 2.98$ & $29.05 \pm 2.98$ & $56.91 \pm 4.71$ & $43.09 \pm 4.71$ \\
10 & $60.76 \pm 3.48$ & $39.24 \pm 3.48$ & $43.43 \pm 4.01$ & $56.57 \pm 4.01$ \\
21 & $64.72 \pm 0.02$ & $35.28 \pm 0.02$ & $48.32 \pm 0.24$ & $51.68 \pm 0.24$ \\
\hline
\end{tabular}

The QFASA model calculations for the subset of extended-dietary FAs gave the proportion of Cryptomonas in the diet of between $29.72 \%$, when CC based on Chlorella were used, and 57.37\%, when CC based on Cryptomonas were used (Table 6). The model calculations for the subset of dietary FAs gave the proportion of Cryptomonas in the diet of between $29.05 \%$, when CC based on Chlorella were used, and $56.57 \%$, when CC based on Cryptomonas were used (Table 7). In all variants of the calculations, the proportion 
of consumed Cryptomonas increased from Day 5 to 10 and then decreased at Day 21 (Tables 6 and 7).

\section{Discussion}

We conducted a simple feeding experiment under close to natural conditions by simulating the switching of Daphnia feeding from a single alga to two algae species in nearly equal proportions. In this simplest case, the tested models produced ambiguous results. The IsoError mixing model gave erroneous results when applied to isotope values of 16:3n-3 and 18:2n-6. These erroneous results could be explained in several ways. First, the signature difference between food sources should not be lower than $2 \%$ [37]. In our study, the isotope values of 16:3n-3 in Chlorella and Cryptomonas were almost equal. Therefore, we had abnormally high standard error values for this FA and an erroneous result. Second, according to Equation (2), the isotope values of consumers should be within the range of isotope values of their food sources. In our study, the isotope values of 16:3n-3 and 18:2n-6 of Daphnia were outside the range of the isotope values of these FAs in the algae. In such a situation, it is most often assumed that there is an additional food source that has not been considered or that there is uncertainty in the isotope values of the food and the consumer, which is caused by, e.g., sampling and measurement errors [16]. As a consequence, we had meaningless negative values for the isotope values of $16: 3 n-3$ and 18:2n-6.

For 18:3n-3, the calculations might provide a more realistic picture, but three questions arise: (1) Why is there such a profound difference between results obtained using the essential 18:2n-6 and 18:3n-3 FAs? (2) Why did a $~ 3$-fold decrease in the proportion of consumed Chlorella and a corresponding increase in the proportion of Cryptomonas occur? (3) Why were isotope values of 18:3n-3 in Daphnia so different in Run III and Runs I and II at Day 10 despite similar initial conditions of the runs?

We do not see any in principle differences between 18:2n-6 and 18:3n-3, since both these FAs cannot be synthesized by the consumer and, thus, must be obtained from food. Their roles in the consumer organisms are not clear, but they are likely to be the precursors of synthesis of long-chain FAs, 20:4n-6 and 20:5n-3, respectively, which, in turn, are the precursors of synthesis of eicosanoid signaling molecules [40-44]. Thus, if the IsoError, based on CSIA, were a reliable approach for the evaluation of diet, both 18:2n-6 and 18:3n-3 would give similar results.

With respect to the second question, the primary reason for the change in the proportions of consumed food items whose concentrations in the medium had been equal was selective feeding of the consumer. There is some evidence of selective feeding of Daphnia, including preferable consumption of Cryptomonas [4,45-47]. Nevertheless, if the model prediction of the $\sim 3$-fold decrease in the proportion of consumed Chlorella and the corresponding increase in the proportion of Cryptomonas is true, this change in food selection of Daphnia during the experiment is difficult to explain.

Concerning the third question, only Run III lasted until Day 21. Then, Run III significantly affected the final results of IsoError. However, in Run III, the isotope values of 18:3n-3 in Daphnia at Days 10 and 21 were the most depleted and closest to the isotope values of Cryptomonas. At present, we cannot explain the variability of isotope values between the runs that had similar initial conditions.

Because of the strong limitations in the selection of suitable fatty acids for the IsoError based on CSIA-FA, of the entire set of fatty acids, only one (18:3n-3) was found to be suitable. Since 20:5n-3, which is physiologically valuable for Daphnia, can be synthesized from 18:3n-3, its metabolic transformations could affect the isotopic ratios of 18:3n-3 in Daphnia. In the treatment where Daphnia consumed Chlorella, some of 18:3n-3 could probably be used for the synthesis of 20:5n-3, which is supported by the presence of 20:5n-3 in Daphnia (Chl) and the absence of this FA in Chlorella. In the treatment where Daphnia consumed Cryptomonas, the animals received a large amount of 20:5n-3 from food and did not need to synthesize this FA. The fractionation coefficients for 18:3n-3 obtained when 
growing Daphnia on a mono-species diet may be incorrect when used for a mixed-algal diet. The metabolic transformation of fatty acids is currently not well understood and deserves careful study [48]. Thus, differences in metabolic isotope fractionation of 18:3n-3 in Daphnia (Chl) and Daphnia (Cry) may cause misinterpretation of the results.

Since there are no reliable answers to the three above questions, or the erroneous results for the two FAs, the use of the IsoError model based on CSIA-FA seems to be unsuitable for evaluating the feeding spectra of zooplankton.

In the QFASA model for both subsets of FAs, namely extended-dietary FAs and dietary FAs, the proportion of Chlorella in the Daphnia diet decreased and then increased, while, in contrast, the proportion of Cryptomonas increased and then decreased. In the middle of the experiment (Day 10), the proportion of Cryptomonas consumed by Daphnia increased from $\sim 30-45 \%$ to $\sim 40-57 \%$. This preference could be due to the requirement of Daphnia for 20:5n-3, since this FA is the determinant of growth and development for this genus [49-55]. When an optimal storage of 20:5n-3 was achieved, Daphnia increased the proportion of consumed Chlorella to $\sim 48-65 \%$ (Day 21 ), since Cryptomonas is generally not a very good food for this genus $[56,57]$. The ranges presented cover the maximum variation in consumption of the two algae species, because calculations were performed with CCs based on Chlorella and Cryptomonas.

In contrast to IsoError, for QFASA, it was possible to use a large number of FAs, which is an important advantage of this method. For example, the two subsets of FAs for QFASA that we used were almost twice as different in the number of FAs but showed similar results. In addition, markers of both types of algae were used in QFASA, including those fatty acids that were found in only one of the species, thereby preventing underestimation of the proportion for one of the species.

Based on our findings, combined with data from the literature, we conclude that the QFASA model is the more reliable method to assess the contributions of different food sources to the diet of zooplankton.

Author Contributions: Conceptualization, M.G., O.M. and N.S.; methodology, I.P., O.M., N.S., E.K., O.A.; software, M.G., I.P.; validation, M.G. and N.S.; formal analysis, O.M., N.S., E.K., O.A.; investigation, O.M., E.K., O.A.; data curation, M.G.; writing-original draft preparation, M.G. and I.P.; writing-review and editing, O.M.; visualization, M.G. and O.M.; supervision, M.G.; project administration, O.M.; funding acquisition, M.G. All authors have read and agreed to the published version of the manuscript.

Funding: This research was funded by the state assignment within the framework of the Basic Research Program of the Russian Federation (topic No. 51.1.1) and the state assignment of the Ministry of Science and Higher Education of the Russian Federation to the Siberian Federal University (Project No. FSRZ-2020-0006 Biologically active substances in environmental, biotechnological and medical systems).

Institutional Review Board Statement: Not applicable.

Informed Consent Statement: Not applicable.

Data Availability Statement: The datasets generated during and/or analyzed during the current study are available from the corresponding author on reasonable request.

Acknowledgments: The authors gratefully thank E.L. Krasova for linguistic check and improvements and P.P. Kormilets for creating illustrations.

Conflicts of Interest: The authors declare no conflict of interest.

\section{References}

1. Knisely, K.; Geller, W. Selective feeding of four zooplankton species on natural lake phytoplankton. Oecologia 1986, 69, 86-94. [CrossRef]

2. Galloway, A.W.E.; Brett, M.T.; Holtgrieve, G.W.; Ward, E.J.; Ballantyne, A.P.; Burns, C.W.; Kainz, M.J.; Mueller-Navarra, D.C.; Persson, J.; Ravet, J.L.; et al. A Fatty Acid Based Bayesian Approach for Inferring Diet in Aquatic Consumers. PLoS ONE 2015, 10, e0129723. [CrossRef] 
3. Porter, K.G. Enhancement of Algal Growth and Productivity by Grazing Zooplankton. Science 1976, 192, 1332-1334. [CrossRef] [PubMed]

4. Gladyshev, M.I.; Emelianova, A.Y.; Kalachova, G.S.; Zotina, T.; Gaevsky, N.A.; Zhilenkov, M.D. Gut content analysis of Gammarus lacustris from a Siberian lake using biochemical and biophysical methods. Hydrobiologia 2000, 431, 155-163. [CrossRef]

5. Kolmakov, V.I.; Gladyshev, M.I. Growth and potential photosynthesis of cyanobacteria are stimulated by viable gut passage in crucian carp. Aquat. Ecol. 2003, 37, 237-242. [CrossRef]

6. Brown, R.J. Freshwater Mollusks Survive Fish Gut Passage. ARCTIC 2009, 60, 124-128. [CrossRef]

7. Iverson, S.; Field, C.; Bowen, W.D.; Blanchard, W. Quantitative fatty acid signature analysis: A new method of estimating predator diets. Ecol. Monogr. 2004, 74, 211-235. [CrossRef]

8. Koussoroplis, A.-M.; Bec, A.; Perga, M.-E.; Koutrakis, E.; Desvilettes, C.; Bourdier, G. Nutritional importance of minor dietary sources for leaping grey mullet Liza saliens (Mugilidae) during settlement: Insights from fatty acid $\delta^{13} \mathrm{C}$ analysis. Mar. Ecol. Prog. Ser. 2010, 404, 207-217. [CrossRef]

9. Wang, S.W.; Hollmén, T.E.; Iverson, S.J. Validating quantitative fatty acid signature analysis to estimate diets of spectacled and Steller's eiders (Somateria fischeri and Polysticta stelleri). J. Comp. Physiol. B 2009, 180, 125-139. [CrossRef] [PubMed]

10. Bec, A.; Perga, M.-E.; Koussoroplis, A.; Bardoux, G.; Desvilettes, C.; Bourdier, G.; Mariotti, A. Assessing the reliability of fatty acid-specific stable isotope analysis for trophic studies. Methods Ecol. Evol. 2011, 2, 651-659. [CrossRef]

11. Budge, S.M.; Penney, S.N.; Lall, S.P. Estimating diets of Atlantic salmon (Salmo salar) using fatty acid signature analyses; validation with controlled feeding studies. Can. J. Fish. Aquat. Sci. 2012, 69, 1033-1046. [CrossRef]

12. Braeckman, U.; Provoost, P.; Sabbe, K.; Soetaert, K.; Middelburg, J.J.; Vincx, M.; Vanaverbeke, J. Temporal dynamics in a shallow coastal benthic food web: Insights from fatty acid biomarkers and their stable isotopes. Mar. Environ. Res. 2015, 108, 55-68. [CrossRef]

13. Guerrero, A.I.; Rogers, T.L. Evaluating the performance of the Bayesian mixing tool MixSIAR with fatty acid data for quantitative estimation of diet. Sci. Rep. 2020, 10, 1-14. [CrossRef]

14. Gaillard, B.; Meziane, T.; Tremblay, R.; Archambault, P.; Blicher, M.E.; Chauvaud, L.; Rysgaard, S.; Olivier, F. Food resources of the bivalve Astarte elliptica in a sub-Arctic fjord: A multi-biomarker approach. Mar. Ecol. Prog. Ser. 2017, 567, 139-156. [CrossRef]

15. Makhutova, O.N.; Shulepina, S.P.; Sharapova, T.A.; Kolmakova, A.A.; Glushchenko, L.A.; Kravchuk, E.S.; Gladyshev, M.I. Intraspecies variability of fatty acid content and composition of a cosmopolitan benthic invertebrate, Gammarus lacustris. Inland Waters 2018, 8, 356-367. [CrossRef]

16. Phillips, D.L. Converting isotope values to diet composition: The use of mixing models. J. Mammal. 2012, 93, 342-352. [CrossRef]

17. Brauns, M.; Berendonk, T.; Berg, S.; Grunicke, F.; Kneis, D.; Krenek, S.; Schiller, T.; Schneider, J.; Wagner, A.; Weitere, M. Stable isotopes reveal the importance of terrestrially derived resources for the diet of the freshwater pearl mussel (Margaritifera margaritifera). Aquat. Conserv. Mar. Freshw. Ecosyst. 2021, 31, 2496-2505. [CrossRef]

18. Verstijnen, Y. Trophic relationships in Dutch reservoirs recently invaded by Ponto-Caspian species: Insights from fish trends and stable isotope analysis. Aquat. Invasions 2019, 14, 280-298. [CrossRef]

19. Moore, J.W.; Semmens, B.X. Incorporating uncertainty and prior information into stable isotope mixing models. Ecol. Lett. 2008, 11, 470-480. [CrossRef] [PubMed]

20. Oeding, S.; Taffs, K.H.; Reichelt-Brushett, A.; Oakes, J.M. Carbon and nitrogen stable isotope analyses indicate the influence of land use on allochthonous versus autochthonous trophic pathways for a freshwater Atyid shrimp. Hydrobiologia 2020, 847, 2377-2392. [CrossRef]

21. Brett, M. Resource polygon geometry predicts Bayesian stable isotope mixing model bias. Mar. Ecol. Prog. Ser. 2014, 514, 1-12. [CrossRef]

22. Meynier, L.; Morel, P.C.H.; Chilvers, B.L.; MacKenzie, D.D.S.; Duignan, P.J. Quantitative fatty acid signature analysis on New Zealand sea lions: Model sensitivity and diet estimates. J. Mammal. 2010, 91, 1484-1495. [CrossRef]

23. Galicia, M.P.; Thiemann, G.W.; Dyck, M.G.; Ferguson, S.H. Characterization of polar bear (Ursus maritimus) diets in the Canadian High Arctic. Polar Biol. 2015, 38, 1983-1992. [CrossRef]

24. Magnone, L.; Bessonart, M.; Rocamora, M.; Gadea, J.; Salhi, M. Diet estimation of Paralichthys orbignyanus in a coastal lagoon via quantitative fatty acid signature analysis. J. Exp. Mar. Biol. Ecol. 2015, 462, 36-49. [CrossRef]

25. Happel, A.; Maier, C.; Farese, N.; Czesny, S.; Rinchard, J. Fatty acids differentiate consumers despite variation within prey fatty acid profiles. Freshw. Biol. 2019, 64, 1416-1426. [CrossRef]

26. Jardine, T.D.; Galloway, A.W.E.; Kainz, M.J. Unlocking the power of fatty acids as dietary tracers and metabolic signals in fishes and aquatic invertebrates. Philos. Trans. R. Soc. B Biol. Sci. 2020, 375, 20190639. [CrossRef]

27. Gladyshev, M.I.; Makhutova, O.N.; Kravchuk, E.S.; Anishchenko, O.V.; Sushchik, N.N. Stable isotope fractionation of fatty acids of Daphnia fed laboratory cultures of microalgae. Limnologica 2016, 56, 23-29. [CrossRef]

28. Gladyshev, M.I.; Temerova, T.A.; Degermendzhy, A.G.; Tolomeev, A.P. Kinetic characteristics of growth of zooplankton in flowing and closed cultivators. Dokl. Akad. Nauk 1993, 33, 795-797.

29. Gladyshev, M.I.; Sushchik, N.N.; Dubovskaya, O.P.; Buseva, Z.; Makhutova, O.N.; Fefilova, E.B.; Feniova, I.Y.; Semenchenko, V.P.; Kolmakova, A.A.; Kalachova, G.S. Fatty acid composition of Cladocera and Copepoda from lakes of contrasting temperature. Freshw. Biol. 2014, 60, 373-386. [CrossRef] 
30. Gladyshev, M.; Sushchik, N.; Gubanenko, G.; Makhutova, O.; Kalachova, G.; Rechkina, E.; Malyshevskaya, K. Effect of the way of cooking on contents of essential polyunsaturated fatty acids in filets of zander. Czech J. Food Sci. 2014, 32, 226-231. [CrossRef]

31. Gladyshev, M.I.; Sushchik, N.N.; Kalachova, G.S.; Makhutova, O.N. Stable Isotope Composition of Fatty Acids in Organisms of Different Trophic Levels in the Yenisei River. PLoS ONE 2012, 7, e34059. [CrossRef]

32. Phillips, D.L.; Gregg, J.W. Source partitioning using stable isotopes: Coping with too many sources. Oecologia 2003, 136, 261-269. [CrossRef] [PubMed]

33. Phillips, D.L. Mixing models in analyses of diet using multiple stable isotopes: A critique. Oecologia 2001, 127, 166-170. [CrossRef]

34. Ben-David, M.; Flynn, R.W.; Schell, D.M. Annual and seasonal changes in diets of martens: Evidence from stable isotope analysis. Oecologia 1997, 111, 280-291. [CrossRef] [PubMed]

35. Brown, C.J.; Brett, M.T.; Adame, M.F.; Stewart-Koster, B.; Bunn, S.E. Quantifying learning in biotracer studies. Oecologia 2018, 187, 597-608. [CrossRef]

36. Sharp, Z. Principles of Stable Isotope Geochemistry, 2nd ed.; University of New Mexico: Albuquerque, NM, USA, 2017. [CrossRef]

37. Phillips, D.L.; Gregg, J.W. Uncertainty in source partitioning using stable isotopes. Oecologia 2001, 127, 171-179. [CrossRef]

38. R Core Team. R: A Language and Environment for Statistical Computing R Foundation for Statistical Computing. Austria. Available online: http:/ / www.R-project.org/ (accessed on 5 September 2021).

39. Team, R. RStudio: Integrated Development for R; RStudio, Inc.: Boston, MA, USA, 2015. Available online: http:/ / www.rstudio.com (accessed on 5 September 2021).

40. Simopoulos, A.P. Omega-3 fatty acids in health and disease and in growth and development. Am. J. Clin. Nutr. 1991, 54, 438-463. [CrossRef] [PubMed]

41. Simopoulos, A.P. Human Requirement for N-3 Polyunsaturated Fatty Acids. Poult. Sci. 2000, 79, 961-970. [CrossRef]

42. SanGiovanni, J.P.; Chew, E.Y. The role of omega-3 long-chain polyunsaturated fatty acids in health and disease of the retina. Prog. Retin. Eye Res. 2005, 24, 87-138. [CrossRef] [PubMed]

43. Heckmann, L.-H.; Sibly, R.M.; Timmermans, M.J.; Callaghan, A. Outlining eicosanoid biosynthesis in the crustacean Daphnia. Front. Zoöl. 2008, 5, 11. [CrossRef] [PubMed]

44. Monroig, T.D.R.; Navarro, J.C. Biosynthesis of polyunsaturated fatty acids in marine invertebrates: Recent advances in molecular mechanisms. Mar. Drugs 2013, 11, 3998-4018. [CrossRef]

45. Feniova, I.; Dawidowicz, P.; Ejsmont-Karabin, J.; Gladyshev, M.; Kalinowska, K.; Karpowicz, M.; Kostrzewska-Szlakowska, I.; Majsak, N.; Petrosyan, V.; Razlutskij, R.; et al. Effects of zebra mussels on cladoceran communities under eutrophic conditions. Hydrobiologia 2018, 822, 37-54. [CrossRef]

46. Feniova, I.; Dawidowicz, P.; Gladyshev, M.I.; Kostrzewska-Szlakowska, I.; Rzepecki, M.; Razlutskij, V.; Sushchik, N.N.; Majsak, N.; Dzialowski, A.R.; Razlutskij, R. Experimental effects of large-bodied Daphnia, fish and zebra mussels on cladoceran community and size structure. J. Plankton Res. 2015, 37, 611-625. [CrossRef]

47. Taipale, S.J.; Vuorio, K.; Brett, M.T.; Peltomaa, E.; Hiltunen, M.; Kankaala, P. Lake zooplankton $\delta^{13} \mathrm{C}$ values are strongly correlated with the $\delta^{13} \mathrm{C}$ values of distinct phytoplankton taxa. Ecosphere 2016, 7, e01392. [CrossRef]

48. Galloway, A.W.E.; Budge, S.M. The critical importance of experimentation in biomarker-based trophic ecology. Philos. Trans. R. Soc. B Biol. Sci. 2020, 375, 20190638. [CrossRef]

49. Von Elert, E. Determination of limiting polyunsaturated fatty acids in Daphnia galeata using a new method to enrich food algae with single fatty acids. Limnol. Oceanogr. 2002, 47, 1764-1773. [CrossRef]

50. Becker, C.; Boersma, M. Differential effects of phosphorus and fatty acids on Daphnia magna growth and reproduction. Limnol. Oceanogr. 2005, 50, 388-397. [CrossRef]

51. Ravet, J.L.; Brett, M.T.; Müller-Navarra, D.C. A test of the role of polyunsaturated fatty acids in phytoplankton food quality for Daphnia using liposome supplementation. Limnol. Oceanogr. 2003, 48, 1938-1947. [CrossRef]

52. Brett, M.T.; Müller-Navarra, D.C.; Ballantyne, A.P.; Ravet, J.L.; Goldman, C.R. Daphnia fatty acid composition reflects that of their diet. Limnol. Oceanogr. 2006, 51, 2428-2437. [CrossRef]

53. Gladyshev, M.I.; Sushchik, N.N.; Dubovskaya, O.P.; Makhutova, O.N.; Kalachova, G.S. Influence of sestonic elemental and essential fatty acid contents in a eutrophic reservoir in Siberia on population growth of Daphnia (longispina group). J. Plankton Res. 2006, 28, 907-917. [CrossRef]

54. Martin-Creuzburg, D.; Sperfeld, E.; Wacker, A. Colimitation of a freshwater herbivore by sterols and polyunsaturated fatty acids. Proc. R. Soc. Boil. Sci. 2009, 276, 1805-1814. [CrossRef] [PubMed]

55. Taipale, S.J.; Kainz, M.J.; Brett, M.T. Diet-switching experiments show rapid accumulation and preferential retention of highly unsaturated fatty acids in Daphnia. Oikos 2011, 120, 1674-1682. [CrossRef]

56. Abrusán, G.; Fink, P.; Lampert, W. Biochemical limitation of resting egg production in Daphnia. Limnol. Oceanogr. 2007, 52, 1724-1728. [CrossRef]

57. Ahlgren, G.; Vrede, T.; Goedkoop, W. Fatty Acid Ratios in Freshwater Fish, Zooplankton and Zoobenthos-Are There Specific Optima? In Lipids in Aquatic Ecosystems; Springer: New York, NY, USA, 2009; pp. 147-178. [CrossRef] 